\title{
AolR
}

Selected Papers of \#AolR2018:

The $19^{\text {th }}$ Annual Conference of the

Association of Internet Researchers

Montréal, Canada / 10-13 October 2018

\section{CONNECTIVE AMBITION AND CREATIVE CAUTION AMONG HOMELESS USERS OF FACEBOOK}

Will Marler

Northwestern University

\section{Introduction}

The popularity and design of social networking sites (SNSs) has led scholars to ask whether any benefit can be observed for the social capital of their users (Ellison et al., 2007). Indeed, Facebook users with more "friends" are more likely to score high on measures of social capital (Burke et al., 2010). This may stem from the ease with which social media users can store latent and weak ties to tap into for future need (Ellison et al., 2007; Ellison, Lampe, et al., 2011). In particular it matters how users engage with others on the site. For example, directed communication appears to yield greater advantage than passive consumption (Burke et al., 2010).

Participation on social media means contending with the virtual architecture of networked publics which departs from conventional means of gauging exposure (boyd, 2011). Users pursue technical and other means to balance their exposure to virtual audiences (Marwick and boyd, 2014). Young people approach the crafting of a social media post with a perception of what is appropriate and who they think is likely to see it (Marwick and Boyd, 2014). Such technical and semantic sophistication may be lacking among populations with typically lower levels of skill in using computers, including older adults and those with less income and education (Ellison, Vitak, et al., 2011).

Social media thus involves its users in a balance of motivation and caution (Ellison, Vitak, et al., 2011). What does this balance look like in practice? I examine the case of unstably housed adults in Chicago to understand how a population susceptible to social isolation and low digital skills navigate their exposure on social media.

\section{Method}

The study is based on in-depth interviews, content analysis and participant-observation. I present two cases in this work-in-progress. Vicki and Eric are unstably housed, white Chicagoans in their late middle age living in a mixed-income, north-side neighborhood. Eric stays in a shelter while Vicki has recently moved into a subsidized studio apartment. Both are daily users of Facebook, Eric exclusively on his Samsung smartphone and Vicki largely on a public-access terminal at a non-profit social service agency. 
The study to date involves a series of three interviews with Vicki and Eric. I also join Vicki and Eric on outings where they engage the neighborhood's homeless community in spiritual outreach and community organization, respectively. I also analyze Vicki and Eric's activity on their multiple Facebook accounts, assessing past activity, friend counts, posts and interactions, and pages and groups. Themes are drawn from field notes, interview transcripts, and content analysis in an iterative, comparative fashion.

\section{Findings}

A perception of Facebook as a gateway to the wider world drives community organizers among the unstably housed of Chicago to "friend" as many others as possible on the site, often to the detriment of their security and privacy. Vicki celebrated the milestone of 1,000 friends, while Eric claimed around 4,500 on his account. Both refer to their local ambitions as motivation to grow their friend count. Lacking a credit card and disposable income, Vicki describes growing her friend count as a "sneaky-clever" means to promote the page of her homeless ministry in lieu of paying Facebook to boost the page. If she can make 5,000 friends, Vicki suggests, she can invite that many directly to like her page. Eric similarly sees his friend count as a metric for the reach of his homeless advocacy. This leads to a rather liberal friending policy. "If someone sends me a request, no problem, l'll accept it," Eric explains.

Beneath the gloss of optimism, a great deal of hassle and concern are apparent. Vicki and Eric each maintain multiple Facebook accounts. Their additional accounts are partly the result of having their primary accounts "hacked." Multiple accounts also Vicki and Eric to segment their virtual presence as advocates and private individuals. Eric reports that his account was "hijacked" by a woman who demanded payment to restore his access. While neither Eric or Vicki have ideas on how their accounts were "hacked", I observed on multiple occasions Vicki sit down at a public-access computer and be pleasantly surprised to find her account already logged in.

Both describe a deluge of requests from strangers, including many users from outside the U.S. who ask for money or even marriage. Vicki relates her consternation at having received persistent requests from an Afghani man who she eventually blocked. In addition to employing this standard technical feature of the site, on her second account, Vicki uses an alternative spelling of her name to conceal herself from the strangers pursuing her on her primary account. Eric has four active Facebook accounts under the same name. Only on one does he pursue his strategy of friending as many others as possible. Even on this account, he reports using profile information and friends lists as a means to determine whether those seeking to connect are "legit." Eric appears to siphon content across his accounts based on genre and propriety. One of Eric's additional accounts is dedicated to his "love of women and cars", and another features primarily posts about medical marijuana and cooking recipes. 


\section{Discussion}

Engaged in community activism for a homeless community of which they are a part, Vicki and Eric turn to Facebook with great hope. They turn to their friend counts as a way of making sense of the technology's potential to connect their causes to the wider world. Such "connective ambition", combined with an uncertain degree of literacy and, in Vicki's case, a reliance on public access, puts them at risk of unwanted attention and online scammers. To take control of their exposure and security, they respond with conventional, technical tactics, such as blocking requesters; conventional filtering tactics, such as probing the accounts of requesters; as well as atypical means, such as establishing multiple accounts under alternative spellings of their names. Marginalized users of social media thus tailor their own strategies to balance ambition and caution in their pursuit of social connection with a cause.

\section{References}

boyd d (2011) Social Network Sites as Networked Publics. In: Papacharissi Z (ed.), $A$ Networked Self: Identity, community, and culture on social network sites, New York: Routledge, pp. 39-58.

Burke M, Marlow C and Lento T (2010) Social network activity and social well-being. In: Proceedings of the SIGCHI conference on human factors in computing systems, ACM, pp. 1909-1912.

Ellison NB, Steinfield C and Lampe C (2007) The benefits of Facebook 'friends:' Social capital and college students' use of online social network sites. Journal of Computer-Mediated Communication, Wiley Online Library 12(4): 1143-1168.

Ellison NB, Vitak J, Steinfield C, et al. (2011) Negotiating privacy concerns and social capital needs in a social media environment. In: Privacy online, Springer, pp. 1932.

Ellison NB, Lampe C, Steinfield C, et al. (2011) With a little help from my friends: How social network sites affect social capital processes. In: The networked self: Identity, community and culture on social network sites, pp. 124-146.

Marwick AE and boyd d (2014) Networked privacy: How teenagers negotiate context in social media. New Media \& Society 16(7): 1051-1067. 